\title{
Prognostic significance and determinants of myocardial salvage assessed by cardiovascular magnetic resonance in acute reperfused myocardial infarction

\author{
Ingo Eitel*, Steffen Desch, Mahdi Sareban, Georg Fuernau, \\ Matthias Gutberlet, Gerhard Schuler and Holger Thiele
}

Address: Heart Center Leipzig, Leipzig, Germany

* Corresponding author

from 13th Annual SCMR Scientific Sessions

Phoenix, AZ, USA. 21 -24 January 2010

Published: 21 January 2010

Journal of Cardiovascular Magnetic Resonance 20 I0, I2(Suppl I):O2 doi:I0.I I86/I532-429X-I2-SI-O2

This abstract is available from: http://jcmr-online.com/content//2/SI/O2

(c) 2010 Eitel et al; licensee BioMed Central Ltd.

\section{Introduction}

In acute myocardial infarction cardiovascular magnetic resonance (CMR) imaging can retrospectively detect the myocardium at risk and the irreversible injury. This allows for quantifying the extent of salvaged myocardium after reperfusion as a potential strong end point for clinical trials and outcome.

\section{Purpose}

The aim of the present study was to determine the prognostic significance and determinants of myocardial salvage assessed by CMR in reperfused ST-elevation myocardial infarction (STEMI).

\section{Methods}

We analyzed 208 consecutive STEMI patients undergoing primary angioplasty $<12$ hours after symptom onset. T2weighted and contrast-enhanced CMR was used to calculate the myocardial salvage index (MSI). Patients were categorized into 2 groups defined by the median MSI. The primary endpoint of the study was occurrence of major adverse cardiovascular events (MACE) defined as death, reinfarction and occurrence of new congestive heart failure within 6 months after the index event.

\section{Results}

The median MSI was 48 (interquartile range, 27-73). MACE was significantly lower in the MSI $\geq$ median group (2.9\% versus $22.1 \%$, p $<0.001)$. The Cox proportional hazards model revealed that MSI was the strongest predictor of MACE at 6 month follow-up ( $\mathrm{p}=0.03)$. All prognostic clinical (symptom-onset-to-reperfusion), angiographic (TIMI-flow grade before angioplasty) and electrocardiographic (ST-segment resolution) parameters showed significant correlations with MSI $(\mathrm{p}<0.001$, respectively).

\section{Conclusion}

This study for the first time demonstrates that MSI assessed by CMR imaging predicts outcome in acute reperfused STEMI. Therefore, MSI assessment has important implications for patient prognosis, as well as for the design of future trials intended to test new reperfusion therapy efficacy. 